The omission of copper oxide would permit the use of shorter porcelain tubes and shorter combustion furnaces. A red hot body of copper oxide hastens breakage of porcelain tubes by causing unequal cooling strains when the furnace flames are lowered or extinguished for any reason. Since February one tube has been in use without copper oxide. The oxide is still retained in the companion tube so that daily comparisons have been made.

LABORATORY OF THE PARK STEEL WORKS,

Crucible steel Co. of America, Pittsburg, Pa, April 26, 1906.

\title{
THE NITROMETER.
}

By J. NEWField aNd J. S. MARX.

Received February I2, I906.

Having occasion to use the nitrometer extensively in our work we have made a study of some of the factors which affect the results obtained by means of this instrument, especially with reference to its use in the analysis of nitrocellulose and other explosives. We have used the form known as Lunge's Improved Nitrometer or Gas Volumeter.

A description of this apparatus is very well given in Sutton's "Volumetric Analysis," eighth edition, pages 6I6 to 6I8. It consists in brief of a decomposing bulb connected by a heavy rubber tube to an overflow. By means of a small piece of rubber tubing this bulb can be connected to a long measuring tube graduated to tenths of cubic centimeters. Temperature and barometric corrections are dispensed with by having a closed tube inserted between the measuring tube and its overflow, all three being joined together by means of a rubber tube. In this sealed tube are $100 \mathrm{cc}$. of air over mercury at $760 \mathrm{~mm}$. pressure and $0^{\circ} \mathrm{C}$. temperature. Thus when the volume of air in the tube is Ioo cc. and the mercury column leveled with that in the measuring tube, its gas is also under the same conditions of temperature and pressure.

However, it would be difficult and also unnecessary to obtain just roo cc. of air in the sealed tube under standard conditions, so a factor is obtained in the following way: Approximately roo cc. of air are introduced into the sealed tube, then a weighed portion of perfectly pure, dry potassium nitrate is run through the apparatus. From its composition I gram of the nitrate gives 22 I cc. of nitric oxide gas, under normal conditions. The differ- 
ence between $22 \mathrm{I} \mathrm{cc}$. and what is actually obtained by experiment "fixes" the factor which is used in all subsequent determinations. About 40 to $50 \mathrm{cc}$. of sulphuric acid are used in making a determination.

\begin{tabular}{|c|c|}
\hline $\begin{array}{l}\text { Strength of acid. } \\
\text { Per cent. }\end{array}$ & $\begin{array}{l}\text { Cubic centimeters of } \\
\text { NO per gram } \mathrm{KNO}_{3} \text {. }\end{array}$ \\
\hline 97.18 & $22 \mathrm{I} . \mathrm{II}$ \\
\hline 96.59 & 221.08 \\
\hline $94.8 \mathrm{I}$ & 221.09 \\
\hline 94.05 & 221.10 \\
\hline 93.02 & 221.60 \\
\hline 90.96 & 223.43 \\
\hline 85.20 & $223.6 \mathrm{I}$ \\
\hline
\end{tabular}

As the original factor is fixed by the use of potassium nitrate, these results only indicate that changes in the concentration of the acid between 97 and 94 per cent. are without effect, but a weaker acid gives too high results, probably because it absorbs less of the nitric oxide. That the stronger acid absorbs nitric oxide was shown by the following experiments: On agitating I I $2 \mathrm{cc}$. of nitric oxide with $40 \mathrm{cc}$. of sulphuric acid of 97 per cent. for three minutes I cc. or 0.89 per cent. was absorbed. On shaking II 2 cc. with $40 \mathrm{cc}$. of an acid of 85 per cent. $0.5 \mathrm{cc}$. or 0.45 per cent. was absorbed.

Determinations made with acid from 85 to 50 per cent. gave widely varying results, indicating that reliable values can not be obtained with such weak acids.

In the analysis of nitrocellulose and similar explosives the strength of the acid is even more important, as will bè seen from. the following table:

Strength of acid
Per cent.
97.18
96.59
$94.8 \mathrm{t}$
94.05
93.02
88.60

Cubic centimeters of nitric
oxide per gram cellulose.

I 99.5

199.5

I99.7

197. I

193. $\mathrm{T}$

I 47.5

Here it is evident that an acid weaker than 94.8 per cent. does: not effect a complete decomposition of the nitrocellulose, probably because the weaker acids do not completely dissolve the guncotton.

Effect of Temperature.-Between $15^{\circ}$ and $40^{\circ}$ the temperature 
at which the decomposition is effected is without appreciable effect on the results obtained either with potassium nitrate or with nitrocellulose. At $40^{\circ}$ or above, loss of nitric acid or oxides of nitrogen occurred on the addition of the sulphuric acid, causing low results.

Effect of Time of Agitation. -The following results were obtained with acid of 97 per cent. at $15^{\circ}$ :

Time of agitation.
Minutes.
I
2
3
5
8

Cubic centimeters of
NO per gram $\mathrm{KNO}_{3}$.
221.07
220.89
220.98
220.97
220.92

Cubic centimeters of No
per gram nitrocellulose.
200.8
$\ldots \ldots .$.
201.9
201.8
201.8

It seems that a complete decomposition of the potassium nitrate is secured in one minute, while three minutes should be used for nitrocellulose.

Effect of Pressure. -The following results were obtained with acid of 97 per cent. at $15^{\circ} \mathrm{C}$, the pressure being roughly calculated from the difference in heights of the mercury columns in the decomposing and overflow bulbs.
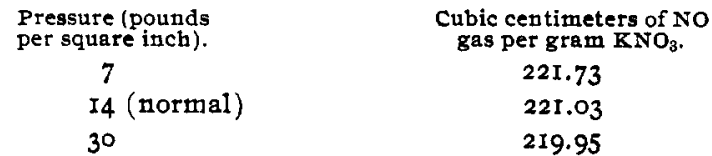

It is seen from the above that the pressure at which the gas exists exerts a marked effect on the results obtained. This is explained by the fact that the higher the pressure exerted on the gas, the more nitric oxide is dissolved in the sulphuric acid. Always keeping the gas at a slightly reduced pressure appears to give very satisfactory and accurate results.

Effect of Standing Dissolved in Sulphuric Acid.-Experiments were carried on with the aim in view of determining if there is any marked difference in results to be noted when organic nitrogenous bodies are allowed to remain for some time in sulphuric acid before decomposing in the nitrometer instead of immediately decomposing as is the method employed here. The results follow. As will be noticed, some of the samples were allowed to stand in ice over night to prevent any possible local heating, but the results do not vary much from those which were simply allowed to stand over night under ordinary conditions. 


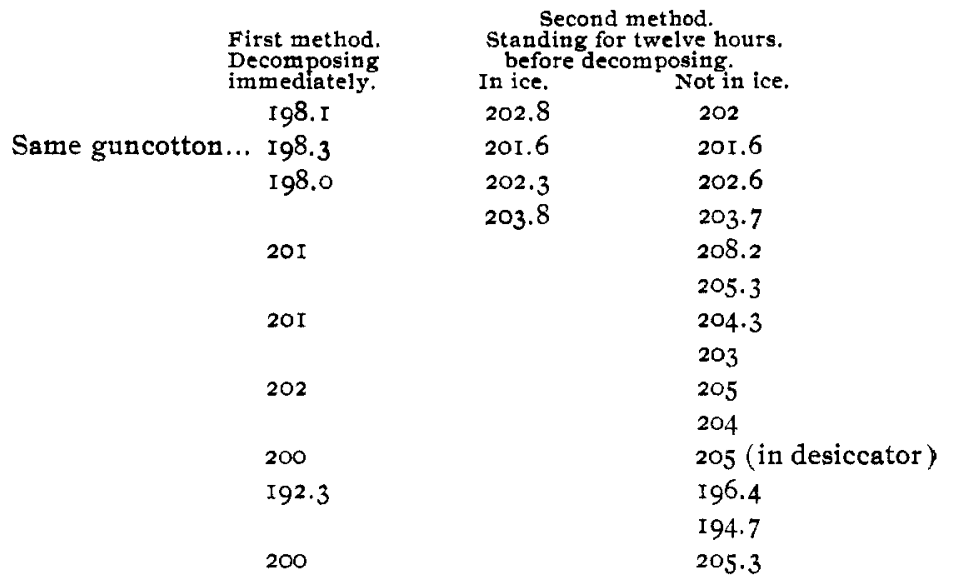

With a view of determining the cause of the above difference, a sample of guncotton weighing 0.6 gram and analyzed in the ordinary way ( $i, e$. , first method) read II $9.7 \mathrm{cc}$. on the nitrometer. The gas was run into strong commercial caustic potash solution and after saturation the loss of gas was found to be only $0.7 \mathrm{cc}$.

Then into this caustic potash solution, saturated with nitric oxide, was run the gas obtained from one of the guncottons which had been analyzed by the second method and the result was as follows:

First method. 200
Second method.

205.3
After absorption. I 96.9

Several checks were made on the above with similar results.

We know that it is impossible for most of the results obtained by the second method to be correct, for extended researches have shown that guncotton having a nitration of $204 \mathrm{cc}$. and upwards is not soluble in a mixture of two parts ether and one part alcohol and yet all these guncottons tested were practically entirely soluble.

Effect of Other Organic Substances. -The following experiments show the effect of the presence of various organic bodies and other substances (many of which occur in dynamites and gelatines) on the determination of nitrogen by the nitrometer.

In every case a weighed portion of potassium nitrate (about $0.55 \mathrm{gram}$ ) was taken and from 0.05 to 0. I gram of substance was 
added. The mixture was allowed to stand over night in sulphuric acid and was then run through the nitrometer. Of course, in this case standing over night does not affect the result as there is no organic matter present which can be decomposed and the small amount of nitric oxide gas lost is constant in all determinations, including those in which the factors were determined.

Results are tabulated as follows:

\begin{tabular}{|c|c|c|c|c|c|}
\hline No. & $\begin{array}{l}\text { Substance. } \\
\text { Resin }\end{array}$ & $\begin{array}{c}\text { Amount taken. } \\
\text { Gram. } \\
\text { o.I }\end{array}$ & $\begin{array}{c}\text { Result in cc. } \\
212.4\end{array}$ & $\begin{array}{l}\text { Result with } \\
\text { chromic acid. }\end{array}$ & $\begin{array}{c}\text { Result after } \\
\text { absorption } \\
\text { with KOH }\end{array}$ \\
\hline 2 & " & O.I & & 2I9. I & 214.9 \\
\hline 3 & Camphor & 0.1 & 203.4 & & \\
\hline 4 & $"$ & O.I & & 219.4 & I99.8 \\
\hline 5 & Sulphur & $0 . I$ & $225 \cdot 3$ & & \\
\hline 6 & " & 0.15 & 227.3 & & \\
\hline 7 & Paraffin & 0.1 & I99.5 & & \\
\hline 8 & " & 0.05 & 209.5 & & \\
\hline 9 & Vaseline & 0.2 & 217.6 & & \\
\hline 10 & " & 0.05 & 218.7 & & \\
\hline II & $\mathrm{MgCO}_{3}$ & 0.05 & 223.4 & & \\
\hline 12 & & & 221.0 & & \\
\hline
\end{tabular}

The following can be deduced from the results. All the organic compounds, as in I, 3, 7 and 9, affect the results in such a way as to give low values. Paraffin has the greatest effect, then camphor, then resin, then vaseline. The effect of adding chromic acid, as seen by the absorption results of potassium hydroxide, is to oxidize some of the carbon to carbon dioxide and thus raise the results, but practically no more nitric oxide is obtained by this treatment. In the table, 2 and 4 show this.

The two inorganic substances used, sulphur and magnesium carbonate, on the contrary, tend to make the result a little high. This is explained in the first case by the formation of a little sulphur dioxide and in the second case by the formation of a little carbon dioxide which is retained by the sulphuric acid and expelled during the violent shaking in the decomposing bulb. This latter is similar to the cases already cited where carbon dioxide is formed when organic nitrogenous compounds are allowed to remain over night in the sulphuric acid before decomposing in the nitrometer.

In summing up the above results we can at once see that the nitrometer is a very delicate instrument, by which, when all 
standard conditions are adhered to, very accurate results may be quickly obtained.

The scope of its usefulness, however, is somewhat limited and a great number of details, apparently trivial, affect the results to a considerable extent.

\title{
THE DETERMINATION OF SILICA IN IRON ORES CONTAIN. ING ALUMINA.
}

\author{
By GRAEAM DRAN,
}

Received April I8, rgo6.

I HAVE found that if the insoluble residue left on the treatment of an iron ore with acids is ignited for a short time the aluminum which it contains is converted into a form which dissolves in concentrated hydrochloric acid. On the basis of this fact the following rapid method for the determination of silica in such ores has been developed.

One gram of the finely powdered ore is dissolved on the hot plate in concentrated hydrochloric acid, using an initial amount of $25 \mathrm{cc}$. Boil until the iron is completely dissolved, adding two or three drops of nitric acid near the end. If pyrites is present, more nitric acid may be required. Nearly all iron ores will yield to this treatment; if an ore does not, the results are worthless.

Evaporate the solution to dryness, take up the residue with a small amount of concentrated hydrochloric acid, boiling till the ferric chloride is all dissolved. Dilute slightly, filter and wash thoroughly with hot hydrochloric acid ( $I: I)$. If a determination of alumina is required, this filtrate must be examined as well as the solution obtained below.

Transfer the moist filter and residue to a platinum crucible and burn the filter carefully, as usual. Then set the crucible upright, put on the cover and ignite for two or three minutes over a Dangler burner. I have found that the proper temperature is best secured in a dull or carbon covered platinum crucible. The ignition must not be continued too long and the temperature must be properly regulated. ${ }^{1}$ I have repeatedly attempted to

${ }^{1} \mathrm{Dr}$. Hillebrand explains the results obtained by Mr. Dean by calling attention to the fact that the aluminum of kaolin is rendered soluble in hydrochloric acid by gentle ignition. See McNeil : This Journa1, 28, 592. If the ignition is too intense, the aluminum becomes insoluble again. If this explanation is correct, the method would not be reliable for ores containing other silicates than kaolin.-EDITOR. 